\title{
PENELITIAN PENAMBAHAN BAHAN LIMBAH TETES TEBU DARI PABRIK GULA MERITJAN PADA CAMPURAN ASPAL BETON
}

\author{
Nanda Ade Kurniawan *1, Sigit Winarto ${ }^{2}$, Ahmad Ridwan ${ }^{3}$. \\ ${ }^{1}$ Fakultas Teknik, Universitas Kadiri. \\ e-mail:*l nandaadekurniawan29@ gmail.com, ${ }^{2}$ sigit.winarto@unik-kediri.ac.id, ${ }^{3}$ \\ ahmad ridwan@unik-kediri.ac.id
}

\begin{abstract}
Asphalt concrete as a material for road construction has long been known and used widely in road construction. Its use in Indonesia is increasing from year to year. This is because asphalt concrete has several advantages compared to other materials, including a relatively lower price than concrete, its ability to support high vehicle weight loads, and can be made from locally available materials and has good resistance to weather. The purpose of this study was to determine the effect of add sugarcane waste as a concrete asphalt mixture and look for out what percentage of the mixture of molasses waste on asphalt concrete to reach the optimum point. From the calculation of the addition of molasses to the concrete asphalt mixture with levels of 5\%, 10\%, and 15\% yield Marshall Quotient (MQ), namely $395 \mathrm{~kg} / \mathrm{mm}, 293$ $\mathrm{kg} / \mathrm{mm}$, and $817 \mathrm{~kg} / \mathrm{mm}$. From these results, it can be concluded that the addition of molasses with a variation of $15 \%$ has an optimal result compared to $5 \%, 10 \%$ addition of molasses.
\end{abstract}

Keywords : Concrete Asphalt, Molasses Mixture, Marshall Quotient, Road Construction

\begin{abstract}
Abstrak
Aspal beton sebagai bahan untuk konstruksi jalan sudah lama dikenal dan digunakan secara luas dalam pembuatan jalan. Penggunaannya pun di Indonesia dari tahun ke tahun makin meningkat. Hal ini disebabkan aspal beton mempunyai beberapa kelebihan dibanding dengan bahan-bahan lain, diantaranya harganya yang relatif lebih murah dibanding beton, kemampuannya dalam mendukung beban berat kendaraan yang tinggi dan dapat dibuat dari bahan-bahan lokal yang tersedia dan mempunyai ketahanan yang baik terhadap cuaca. Tujuan dari penelitian ini adalah untuk mengetahui pengaruh penambahan bahan limbah tetes tebu sebagai bahan campuran pada aspal beton dan Mengetahui berapa persentase campuran limbah tetes tebu pada aspal beton agar mencapai titik optimum. Dari hasil perhitungan penambahan tetes tebu pada campuran aspal beton dengan kadar 5\%, 10\% dan 15\% menghasilkan Marshall Quotient (MQ) yaitu antara lain $395 \mathrm{~kg} / \mathrm{mm}, 293 \mathrm{~kg} / \mathrm{mm}$, dan $817 \mathrm{~kg} / \mathrm{mm}$. Dari hasil tersebut dapat disimpulkan bahwa penambahan tetes tebu dengan variasi $15 \%$ memiliki hasil yang optimal dibandikan dengan 5\%, $10 \%$ penambahan tetes tebu.
\end{abstract}

Kata Kunci : Aspal Beton, Campuran Tetes Tebu, Marshall Quotient, Konstruksi Jalan 


\section{PENDAHULUAN}

Aspal beton sebagai bahan untuk konstruksi jalan sudah lama dikenal dan digunakan secara luas dalam pembuatan jalan. Penggunaannya pun di Indonesia dari tahun ke tahun makin meningkat. Hal ini disebabkan aspal beton mempunyai beberapa kelebihan dibanding dengan bahan-bahan lain, diantaranya harganya yang relatif lebih murah dibanding beton, kemampuannya dalam mendukung beban berat kendaraan yang tinggi dan dapat dibuat dari bahan-bahan lokal yang tersedia dan mempunyai ketahanan yang baik terhadap cuaca [1][2][3].

Penggunaan campuran aspal beton banyak diteliti untuk mendapatkan kinerja campuran yang baik dan ekonomis, selain itu perlu suatu upaya pemanfaatan material lokal dan bagaimana bahan lokal seperti tetes tebu yang persediaannya melimpah di Pabrik Gula Meritjan tepatnya di daerah Mrican, Kota Kediri, [4][5][6].

Tujuan penelitian ini adalah untuk mengetahui seberapa besar pengaruh campuran aspal beton dengan menggunakan tetes tebu sebagai bahan penambah pada campuran aspal beton, dan bagaimana variasi campuran optimal dalam mencapai stabilitas dan flow yang disyaratkan dengan penggunaan bahan penambah tetes tebu.

\section{METODE PENELITIAN}

\subsection{Laston}

Laston adalah suatu lapis permukaan yang terdiri dari campuran aspal keras sebagai bahan pengikat dan agregat kasar, halus, dan pengisi (filler), dengan cara pencampuran dan pemadatan dalam kondisi panas dan suhu tertentu, [7][8][9].

Aspal yang dipergunakan sebagai material perkerasan jalan berfungsi sebagai berikut, [10][11] :

1. Bahan pengikat, memberikan ikatan yang kuat antara aspal dan agregat dan sesama aspal.

2. Bahan pengisi, mengisi rongga antar butir agregat dan poripori yang ada dalam butir agregat itu sendiri, [12][13].

\subsection{Aspal Beton}

Aspal beton adalah jenis perkerasan jalan yang terdiri dari campuran agregat dan aspal, dengan atau tanpa bahan tambahan [14]. Lapis aspal beton merupakan jenis tertinggi dari perkerasan yang merupakan campuran dari bitumen dengan agregat bergradasi menerus dan cocok untuk jalan yang banyak dilalui kendaraan berat, [15][16]. Material material pembentuk aspal beton dicampur dan diinstalasi pencampur pada suhu tertentu, kemudian diangkut ke lokasi, dihamparkan, dan dipadatkan. Suhu pencampuran ditentukan berdasarkan jenis aspal yang akan digunakan. Jika digunakan semen aspal, maka suhu pencampuran umumnya antara $145^{\circ}-155^{\circ} \mathrm{C}$, 
sehingga disebut aspal beton campuran panas. Campuran ini dikenal juga dengan nama hotmix, [8][17].

\subsection{Tetes Tebu}

Tetes tebu (molase) merupakan produk sampingan dari industri pengolahan gula tebu atau gula bit yang masih mengandung gula dan asam-asam organik. Molase yang hasil dari industri gula tebu di Indonesia dikenal dengan nama tetes tebu. Kandungan sukrosa dalam molase cukup tinggi, berkisar 48-55\% sehingga dapat digunakan sebagai sumber yang baik untuk pembuatan etanol. Molase berbentuk cairan kental berwarna cokelat ini dapat dimanfaatkan sebagai bahan baku etanol, alkohol.berikut di bawah ini adalah kandungan yang ada di dalam limbah tetes.

Tabel 1. Kandungan pada Tetes Tebu

\begin{tabular}{|c|c|c|c|c|c|}
\hline \multirow{2}{*}{ No } & \multicolumn{5}{|c|}{ Kandungan Tetes Tebu \% } \\
\cline { 2 - 6 } & Brix & Pol & HK & TSAI & OD \\
\hline 1 & $6,87 \%$ & $48,9 \%$ & $6,98 \%$ & $7,82 \%$ & $97 \%$ \\
\hline
\end{tabular}

Sumber : Laboratorium pabrik gula Meritjan

Keterangan :

- Brix : Kadar Kotoran + gula

- Pol : Kadar gula

- HK : harga kemurnian (Pol/brix)

- TSAI : Kadar gula tapi bukan gula - OD : kekentalan warna

\subsection{Tahapan Pelaksanaan}

Tahapan - tahapan pelaksanaan penelitian ini mencakup persiapan, pelaksanaan dan analisa data, [18][19][20]. Persiapan dimulai dengan dilakukan studi literature terlebih dahulu dengan mengumpulkan referensi berupa buku atau jurnal yang berhubungan dengan judul dari penelitian ini, kemudian dilanjutkan dengan persiapan alat yang sudah tersedia di laboratorium serta pengadaan material yang didapatkan dari PUPR Kabupaten Nganjuk berupa aspal, Pasir dan koral dan tetes tebu didapat daptkan dari laboratorium pabrik gula meritjan Kediri. Selanjutnya dilakukan pengujian agregat kasar dan agregat halus yang melingkupi pengujian analisa saringan, berat jenis, dan penyerapan air pada agregat, sedangkan filler hanya dilakukan pengujian analisa saringan saja. Secara garis besar, tahapan alur penelitian daat dilihat seperti bagan di bawah ini :

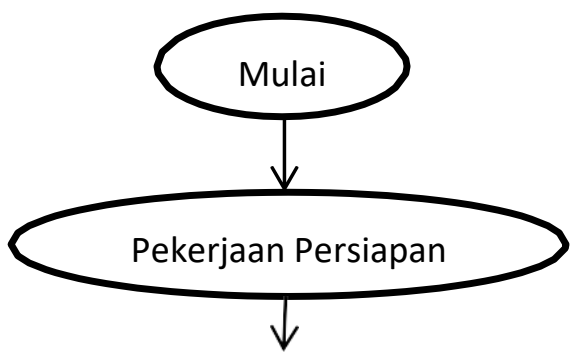




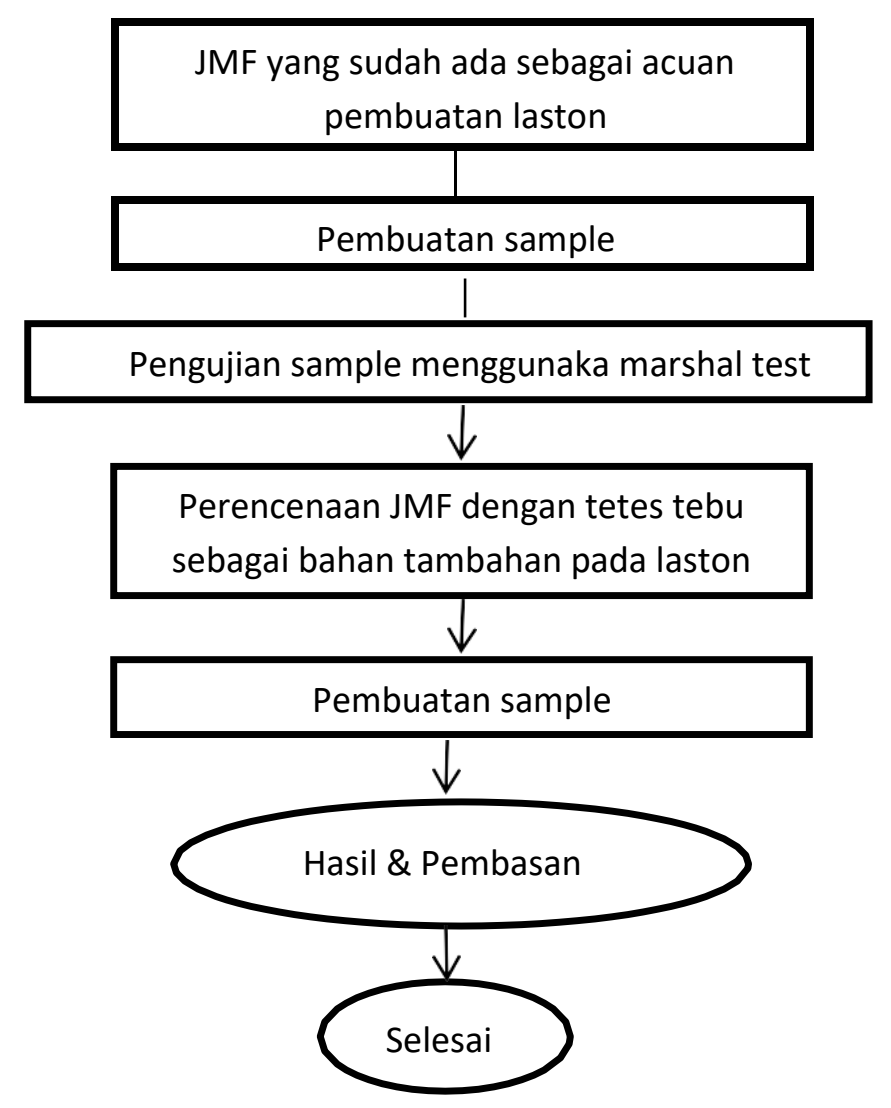

Sumber : Analisa Pengamatan

Gambar 1. Alur penelitian

\subsection{Persiapan JMF ( Job Mix Formula)}

Dalam Penelitian kali ini menggunakan JMF (Job Mix Formula) yang sudah ada.

Tabel 2. Proporsi campuran agregat pada Laston / AC-(L)

\begin{tabular}{|c|c|c|c|c|c|c|c|}
\hline No & Bahan & \multicolumn{2}{|c|}{ Jumlah \% } & \multicolumn{2}{|c|}{ Individual } & \multicolumn{2}{c|}{ Comulative } \\
\hline 1 & Agragat Kasar & 25 & $\%$ & 300 & gram & 300 & gram \\
\hline 2 & Agragat Medium & 33 & $\%$ & 396 & gram & 696 & gram \\
\hline 3 & Agragat Halus & 40 & $\%$ & 480 & gram & 1176 & gram \\
\hline 4 & Filler & 2 & $\%$ & 24 & gram & 1200 & gram \\
\hline
\end{tabular}

Sumber : (Data (JMF) Job Mix Formula Acuan)

Tabel 3. Penyesuaian proporsi campuran Laston / AC-(L)

\begin{tabular}{|c|c|c|c|c|c|c|c|}
\hline No & Bahan & \multicolumn{2}{|c|}{ Jumlah \% } & \multicolumn{2}{c|}{ Individual } & \multicolumn{2}{c|}{ Comulative } \\
\hline 1 & Agragat Kasar & 23.43 & $\%$ & 281 & gram & 281.2 & gram \\
\hline 2 & Agragat Medium & 30.92 & $\%$ & 371 & gram & 652.2 & gram \\
\hline 3 & Agragat Halus & 37.48 & $\%$ & 450 & gram & 1102 & gram \\
\hline 4 & Filler & 1.87 & $\%$ & 22 & gram & 1124 & gram \\
\hline 5 & Aspal & 6.3 & $\%$ & 76 & gram & 1200 & gram \\
\hline
\end{tabular}


Sumber : (Data (JMF) Job Mix Formula Acuan)

\subsection{Perancangan Campuran / Mix Design}

Setelah pengujian seluruh material penyusun yang diperlukan maka langkah berikutnya yaitu merancang campuran agar diperoleh komposisi campuran sesuai dengan target yang diharapkan, [3].

a) Proporsi campuran agregat pada Laston /AC-(L) dengan tetes tebu 5\%

b) Proporsi campuran agregat pada Laston / AC-(L) dengan tetes tebu 10\%

c) Proporsi campuran agregat pada Laston / AC-(L) dengan tetes tebu 15\%

\subsection{Pengujian Sample}

1. Bersihkan benda uji dari kotoran yang menempel.

2. Berilah nomor pada masingmasing benda uji.

3. Ukur tinggi benda uji tersebut gunakan mistar yang presisi.

4. Timbang benda uji dengan timbangan yang sensitive.

5. Rendam benda uji dalam air kira-kira 24 jam pada suhu ruang.

6. Timbang dalam air untuk mendapatkan berat isi, setelah itu timbang lagi benda uji tesebut dalam kondisi kering permukaan jenuh (benda uji diusap dengan handuk).

7. Rendamlah benda uji aspal panas atau benda uji tar dalam bak perendam (Waterbath) selama 30 sampai 40 menit atau dipanaskan didalam oven selama 2 jam dengan suhu tetap 60oC.

8. Sebelum pembebanan diberikan, kepala penekan beserta benda ujinya dinaikkan hingga menyentuh alas cincin penguji. Atur kedudukan jarum dial dengan kecepatan tetap sebesar $50 \mathrm{~mm} / \mathrm{menit}$.

9. Menghitung parameter marshal

\section{HASIL DAN PEMBAHASAN}

\subsection{Hasil Pemeriksaan Karakteristik Aspal}

Hasil pengujian karakteristik aspal minyak menggunakan metode SNI [20], dapat dilihat pada tabel 4.

Tabel 4. Tabel Pengujian

\begin{tabular}{|l|l|l|l|l|l|}
\hline \multirow{2}{*}{ No } & \multirow{2}{*}{ Pengujian } & \multirow{2}{*}{ hasil } & \multicolumn{2}{|l|}{ Spesifikasi } & \multirow{2}{*}{ satuan } \\
\cline { 4 - 5 } & & & Min. & Max. & \\
\hline 1 & $\begin{array}{l}\text { Penetrasi } 25^{\circ} \text { Sebelum kehilangan } \\
\text { berat }\end{array}$ & 65 & 60 & 79 & $\begin{array}{c}0,1 \\
\mathrm{~mm}\end{array}$ \\
\hline 2 & Titik Lembek & 52 & 48 & 58 & ${ }^{\circ} \mathrm{C}$ \\
\hline
\end{tabular}




\begin{tabular}{|l|l|l|l|l|l|}
\hline 3 & Daktilitas pada $25^{\circ} \mathrm{C}$ & 115 & 100 & - & $\mathrm{Cm}$ \\
\hline 4 & Titik nyala & 320 & 200 & - & ${ }^{\circ} \mathrm{C}$ \\
\hline 5 & Berat Jenis & 1,01 & 1 & - & \\
\hline 6 & Kehilangan Berat & 0,2 & - & 0,8 & $\%$ \\
\hline 7 & $\begin{array}{l}\text { Penetrasi } 25^{\circ} \text { Setelah kehilangan } \\
\text { berat }\end{array}$ & 85 & 54 & - & $\begin{array}{l}0,1 \\
\mathrm{~mm}\end{array}$ \\
\hline
\end{tabular}

Sumber : Laboratorium Fakultas Teknik Universitas Kadiri

\subsection{Penentuan Gradasi Campuran}

Propersi agregat gabungan didapatkan dari nilai perbandingan komposisi rencana dikalikan dengan nilai persen lolos pada analisa saringan. Setelah itu, hasil yang diperoleh untuk semua komponen yaitu 1-2 cm, 0,5-1 cm, agregat halus, dan filler kemudian dijumlahkan. Selanjutnya, proporsi agregat gabungan yang telah diperoleh tersebut disesuaikan dengan nilai interval spesifikasi. Untuk lebih jelasnya diulas pada tabel 5.

Tabel 5. Penentuan Gradasi Campuran

\begin{tabular}{|c|c|c|c|c|}
\hline \multirow{2}{*}{ No } & \multirow{2}{*}{ ukuran saringan } & Spesifikasi & \multicolumn{2}{|c|}{$\begin{array}{c}\text { Rancaangan } \\
\text { Gradasi }\end{array}$} \\
\cline { 3 - 5 } & & $\begin{array}{c}\% \\
\text { Lolos }\end{array}$ & $\begin{array}{c}\% \\
\text { Lolos }\end{array}$ & \begin{tabular}{c}
$\%$ Tertahan \\
\cline { 3 - 5 }
\end{tabular} \\
\cline { 3 - 5 } & $3 / 4 "$ & 100 & 100 & 0 \\
\hline 2 & $1 / 2^{\prime \prime}$ & $90-100$ & 95 & 5 \\
\hline 3 & $3 / 8^{\prime \prime}$ & $77-90$ & 81 & 14 \\
\hline 4 & $4 "$ & $53-69$ & 55 & 26 \\
\hline 5 & $8 "$ & $33-53$ & 38 & 17 \\
\hline 6 & $16 "$ & $21-40$ & 27 & 11 \\
\hline 7 & $30 "$ & $14-30$ & 19 & 8 \\
\hline 8 & $50 "$ & $09-22$ & 14 & 5 \\
\hline 9 & $100 "$ & $06-15$ & 10 & 4 \\
\hline 10 & $200 "$ & $04-09$ & 6 & 4 \\
\hline 11 & FILLER & 0 & 0 & 6 \\
\hline
\end{tabular}

Sumber : Analisa Pengamatan

\subsection{Data dan Perhitungan}

Berikut ini merupakan pengolahan data uji karakteristik marshal yang disajikan menggunakan tabel seperti dibawah ini : 
Tabel 6. Data Tinggi dan Diameter Benda Uji

\begin{tabular}{|c|c|c|c|c|c|c|c|}
\hline $\begin{array}{l}\text { Kadar } \\
\text { Aspal } \\
(\%)\end{array}$ & $\begin{array}{c}\text { Kadar } \\
\text { Tetes } \\
\text { tebu } \\
(\%)\end{array}$ & $\begin{array}{l}\text { Berat } \\
\text { Aspal } \\
\text { (gram) }\end{array}$ & $\begin{array}{l}\text { Tinggi } \\
(\mathrm{cm})\end{array}$ & $\begin{array}{l}\text { Tinggi } \\
\text { Rata } \\
\text { rata } \\
(\mathrm{cm})\end{array}$ & $\begin{array}{c}\text { Diameter } \\
(\mathrm{cm})\end{array}$ & $\begin{array}{c}\text { Diameter } \\
\text { Rata-rata } \\
\quad(\mathrm{cm})\end{array}$ & Volume \\
\hline 5 & 5 & 60 & 7 & \multirow[t]{3}{*}{6,8} & 10,09 & \multirow[t]{3}{*}{10,09} & 559,43 \\
\hline 5 & 5 & 60 & 6,9 & & 10,09 & & 551,44 \\
\hline 5 & 5 & 60 & 6,7 & & 10,09 & & 535,45 \\
\hline 5 & 10 & 60 & 7,1 & \multirow[t]{3}{*}{7} & 10,09 & \multirow[t]{3}{*}{10,09} & 567,42 \\
\hline 5 & 10 & 60 & 7,1 & & 10,09 & & 567,42 \\
\hline 5 & 10 & 60 & 6,9 & & 10,09 & & 551,44 \\
\hline 5 & 15 & 60 & 7 & \multirow[t]{3}{*}{6,8} & 10,09 & \multirow[t]{3}{*}{10,09} & 559,43 \\
\hline 5 & 15 & 60 & 6,9 & & 10,09 & & 551,44 \\
\hline 5 & 15 & 60 & 6,7 & & 10,09 & & 535,45 \\
\hline
\end{tabular}

Sumber : Laboratorium Fakultas Teknik Universitas Kadiri.

Tabel 7. Berat Benda Uji

\begin{tabular}{|c|c|c|c|c|c|}
\hline $\begin{array}{l}\text { Kadar } \\
\text { Aspal } \\
(\%)\end{array}$ & $\begin{array}{c}\text { Kadar } \\
\text { Tetes Tebu } \\
(\%)\end{array}$ & $\begin{array}{c}\text { Berat } \\
\text { Kering } \\
\text { gram })\end{array}$ & $\begin{array}{c}\text { Berat } \\
\text { Jenuh (ssd) } \\
\text { (gram) }\end{array}$ & $\begin{array}{c}\text { Berat } \\
\text { Dlm air } \\
(\text { gram })\end{array}$ & Berat Isi \\
\hline 5 & 5 & 1266 & 1270 & 740 & 530 \\
\hline 5 & 5 & 1209 & 1190 & 711 & 479 \\
\hline 5 & 5 & 1123 & 1133 & 605 & 528 \\
\hline 5 & 10 & 1280 & 1282 & 780 & 502 \\
\hline 5 & 10 & 1233 & 1239 & 708 & 531 \\
\hline 5 & 10 & 1158 & 1177 & 611 & 566 \\
\hline 5 & 15 & 1269 & 1280 & 784 & 496 \\
\hline 5 & 15 & 1231 & 1230 & 760 & 470 \\
\hline 5 & 15 & 1210 & 1212 & 741 & 471 \\
\hline
\end{tabular}

Sumber : Laboratorium Fakultas Teknik Universitas Kadiri.

\subsection{Perhitungan Menentukan Berat Aspal (5\%)}

a. Kadar Tetes Tebu 5\%

$>$ Sample $1=1266: 95 \%=1332,63$

$>$ Sample $2=1209: 95 \%=1272,63$

$>$ Sample $3=1123: 95 \%=1182,10$

$>$ Berat aspal Sample $1=1332,63-1266=66,63$ gram

$>$ Berat aspal Sample $2=1272,63-1209=63,63$ gram

$>$ Berat aspal Sample $3=1182,10-1123=59,10$ gram

Benda uji dengan kadar tetes tebu 5\% \& Aspal 5\% 
b. Kadar Tetes Tebu $10 \%$

$>$ Sample $1=1280: 95 \%=1347,36$

$>$ Sample $2=1233: 95 \%=1297,89$

$>$ Sample $3=1158: 95 \%=1218,94$

$>$ Berat aspal Sample $1=1347,36-1280=67,36$ gram

$>$ Berat aspal Sample $2=1297,89-1233=64,89$ gram

$>$ Berat aspal Sample $3=1218,94-1158=60,94$ gram

Benda uji dengan kadar tetes tebu 10\% \& Aspal 5\%

c. Kadar Tetes Tebu $15 \%$

Sample $1=1269: 95 \%=1335,78$

$>$ Sample $2=1231: 95 \%=1295,78$

$>$ Sample $3=1210: 95 \%=1273,68$

$>$ Berat aspal Sample $1=1335,78-1269=66,78$ gram

$>$ Berat aspal Sample $2=1295,78-1231=64,78$ gram

Berat aspal Sample $3=1273,68-1210=63,68$ gram

Benda uji dengan kadar tetes tebu 15\% \& Aspal 5\%

Tabel 8. Hasil pengujian karakteristik Marshall untuk seluruh parameter

\begin{tabular}{|c|c|c|c|c|c|c|c|c|}
\hline No. & $\begin{array}{c}\text { Kadar } \\
\text { Aspal } \\
\%\end{array}$ & $\begin{array}{r}\text { Kadar } \\
\text { Tetes } \\
\text { Tebu } \\
\%\end{array}$ & $\begin{array}{c}\text { VMA } \\
\%\end{array}$ & $\begin{array}{c}\text { VIM } \\
\%\end{array}$ & $\begin{array}{c}\text { VFB } \\
\%\end{array}$ & Stabilitas & Flow & MQ \\
\hline 1 & $5 \%$ & $5 \%$ & 27,40 & 8,68 & 68,28 & 880 & 2,23 & 394 \\
\hline 2 & $5 \%$ & $10 \%$ & 27,27 & 8,52 & 68,74 & 516 & 1,76 & 293 \\
\hline 3 & $5 \%$ & $15 \%$ & 26,47 & 7,52 & 71,58 & 458 & 1,6 & 286 \\
\hline 4 & Spes & ikasi & $15 \%<$ & $3-5 \%$ & $65 \%<$ & $800 \mathrm{~kg}$ & $\begin{array}{c}2-4 \\
\mathrm{~mm}\end{array}$ & Min 300 \\
\hline
\end{tabular}

Sumber : Laboratorium Fakultas Teknik Universitas Kadiri

\section{KESIMPULAN}

Penelitian ini telah dilakukan di Laboratorium Fakultas Teknik Universitas Kadiri dengan hasil sebagai berikut :

1. Dari hasil penelitian, untuk penambahan tetes tebu pada campuran aspal beton mengalami penurunan pada nilai stabilitas dan dll dari pada campuran aspal beton normal, masingmasing penurunannya dengan pemambahan tetes tebu yaitu antara lain $5 \%$ sebesar $880 \mathrm{~kg}$, $10 \%$ sebesar $517 \mathrm{~kg}, 15 \%$ sebesar $457 \mathrm{~kg}$. 
2. Penambahan tetes tebu pada campuran aspal beton dengan kadar 5\%, $10 \%$ dan $15 \%$ menghasilkan volume rongga udara terhadap campuran (VIM) yaitu antara lain 8,68\%, $, 8,52 \%$, dan $7,52 \%$.

3. Penambahan tetes tebu pada campuran aspal beton dengan kadar 5\%, $10 \%$ dan $15 \%$ menghasilkan volume pori antara butir agregat (VMA) yaitu antara lain 27,40 \%, 27,27 \%, dan $26,47 \%$.

4. Penambahan tetes tebu pada campuran aspal beton dengan kadar 5\%, $10 \%$ dan $15 \%$ menghasilkan volume pori antara butir agregat yang terisi aspal (VFB) yaitu antara lain $74,67 \%, 76,96 \%$, dan 71,58\%.

5. Penambahan tetes tebu pada campuran aspal beton dengan kadar 5\%, 10\% dan 15\% menghasilkan Marshall Quotient (MQ) yaitu antara lain 395 kg/mm, 293 kg/mm, dan 817 $\mathrm{kg} / \mathrm{mm}$.

\section{SARAN}

1. Penambahan tetes tebu berpengaruh terhadap nilai stabilitas.

2. Pada saat mencampurkan adonan aspal beton, sebaiknya dicampurkan secepat mungkin agar aspal tidak cepat menggumpal.

3. Penambahan tetes tebu sangat berpengaruh dengan kwalitas aspal yang akan digunakan.

4. Makanya dari itu masih banyak hal yang perlu dilakukan penelitian lebih lanjut agar pada campuran aspal beton dengan tambahan tetes tebu dapat digunakan pada ruang lingkup pekerjaan teknik sipil yang lebih luas.

\section{UCAPAN TERIMAKASIH}

Dalam penyusunan artikel ini, penulis ucapkan terimakasih kepada dosen pembimbing dan Universitas Kadiri. Penulis berharap agar artikel ini dapat bermanfaat bagi pembaca.

\section{DAFTAR PUSTAKA}

[1] C. Yulianto, Y. Cahyo, A. Ridwan, and A. I. Candra, "PENELITIAN PENAMBAHAN BAHAN ADITIF KAPUR PADAM SEBAGAI BAHAN PENGISI FILLER PADA CAMPURAN ASPAL BETON,” Jurmateks, vol. 1, no. 2, pp. 204-215, 2018.

[2] S. Anam and H. Pratikto, "PENGUJIAN PERKERASAN ASPAL PORUS DENGAN Fakultas Teknik Universitas Kadiri," Ukarst J. Univ. Kadiri Ris. Tek. Sipil, vol. 2, no. 2, pp. 154-163, 2018.

[3] H. Kusharto, "Pengaruh Gradasi Agregat Terhadap Perilaku Campuran Beton Aspal," 2007.

[4] A. Setiawan and A. Vanhardy, "Perencanaan Campuran Aspal Beton dengan 
Menggunakan Filler Portland Cement,” 2010.

[5] A. Y. Bintoro, A. D. Limantara, and S. Winarto, "EVALUASI KEKUATAN CONCBLOCK DENGAN AGREGAT HALUS DAN AGREGAT KASAR DARI TEMPURUNG KELAPA,”Jurmateks, vol. 1, no. 1, pp. 160-171, 2018.

[6] D. Kartikasari and S. D. Hartantyo, "Penggantian Filler Dengan Fly Ash Dan Serbuk Batu Bata Pada Campuran Aspal (Ac-Wc) Filler Replacement With Fly Ash and Brick Powder in Mix of Asphalt (Ac-Wc)," UKaRsT, vol. 1, no. 1, p. 9, 2017, doi: 10.30737/ukarst.v1i1.259.

[7] H. C. Hardiyatmo, "Perkerasan Jalan Beton Dengan Menggunakan Sistem Pelat Terpaku."

[8] Departmen Pekerjaan Umum, Tata Cara Pelaksanaan Lapis Aspal Beton (LASTON) Untuk Jalan Raya. 2010.

[9] S. Winarto and Z. Lubis, "Campuran aspal panas menggunakan metode Konten RAP Tinggi dengan penambahan sasobit," UKaRsT, vol. 1, no. 2, pp. 120-128, 2017.

[10] M. Aminuddin, A. I. Candra, and Y. C. S, "JOB MIX LASTON (AC-BC) MENGGUNAKAN BUBUK GYPSUM DAN ABU BATA MERAH,” Jurmateks, vol. 1, no. 2, pp. 325-335, 2018.

[11] Kimpraswil, "Spesifikasi Umum Perkerasan Aspal,” 2002.

[12] E. Nurfadzilah, S. Winarto, and Y. C. SP, "ANALISA JALAN RING ROAD NGAWI STA 3+200 - STA 6+200 KABUPATEN NGAWI PROPINSI JAWA TIMUR," Jurmateks, vol. 1, no. 1, pp. 33-43, 2018.

[13] B. Marga, "Perkerasan Aspal, Spesifikasi Umum Divisi VI Revisi 3.” Jakarta, 2010.

[14] Maryanto, S. Winarto, and L. D. K, "STUDI EKSPERIMENTAL PENGARUH PENAMBAHAN LIMBAH KUNINGAN TERHADAP KUAT TEKAN BETON MUTU K-225,” Jurmateks, vol. 1, no. 1, pp. 76-90, 2018.

[15] AASHTO, "Standard Specifications for Transportation Materials and Methods of Sampling and Testing and AASHTO Provisional Standards," 1990.

[16] S. Sukirman, Beton Aspal Campuran Panas. 2016.

[17] D. U. Sudarsono, "Rencana Campuran (Mix Design)," p. 1993, 1993.

[18] H. . Jogiyanto, “Analisis dan Desain Sistem Informasi,” pp. 1-5, 2008.

[19] Direktorat Jendral Bina Marga, "Perencanaan Geometrik Jalan," Departemen Pekerjaan Umum. 2017.

[20] Direktorat Jendral Bina Marga, "Petunjuk Pelaksanaan Lapis Aspal Beton (Laston)," no. September, 1981. 